\title{
Espaço perivascular gigante tumafetivo: relato de caso raro de alteração de campo visual associado a cefaleia
}

\author{
Bárbara de Alencar Leite Costa, Luiz Gomes de Sá Neto, Gabriel Taricani Kubota \\ Caio Grava Simioni ${ }^{(\mathbb{D})}$, Marcio Nattan Portes Souza ${ }^{\mathbb{D}}$, Ida Fortini ${ }^{-1}$
}

Hospital das Clínicas da Faculdade de Medicina da Universidade São Paulo, São Paulo, Brasil.

\section{Relato de caso}

Paciente de 60 anos do sexo feminino com história de alteração visual há 2 anos evoluindo com cefaleia após um ano do início dos sintomas. Relato de cefaleia em pressão bilateral de fraca intensidade, relacionada a náuseas, escurecimento visual transitório e zumbido bilateral não pulsátil. Paciente encaminhada ao nosso serviço para avaliação de hipertensão intracraniana idiopática devido achado de alteração em campo visual externo. Ao exame neurológico, paciente apresentava quadrantopsia homônima temporal direita, com fundoscopia sem alterações. Achado confirmado em avalição com neurooftalmologia do serviço e campimetria computadorizada. Ressonância magnética de crânio evidenciou espaço perivascular gigante tumefeito acometendo temporal esquerdo promovendo desvio de tracto óptico ipsilateral, sem sinais indiretos de hipertensão intracraniana. Angioressonância venosa de crânio sem alterações. Exame do líquor evidenciando pressão aumentada ( $\mathrm{Pi}=35 \mathrm{cmH} 2 \mathrm{O})$, sem alterações quimiocitológicas.

\section{Resultado}

Espaço perivasculares são estruturas $<2 \mathrm{~mm}$ preenchidas por fluido ao redor de artérias que são comumente encontrados em exames de imagem de pessoas saudáveis. Em contrapartida, espaços gigantes $(>15 \mathrm{~mm}$ ) são entidades raras que se assemelham a tumores e de localização preferencial tálamo-mesencefálica. Menos de 80 casos foram descritos em literatura, cefaleia é o principal sintoma descrito com achado de hidrocefalia obstrutiva como causa. O principal diagnóstico diferencial de hipertensão intracraniana idiopática foi excluído na ausência de alteração papilar, alterações típicas ao campo visual bem como de sinais indiretos nos exames de imagem. Essse é um caso de localização atípica dessa entidade rara se manifestando com alteração visual secundária a compressão do tracto óptico e cefaleia.

\section{Conclusão}

Descrevemos um caso raro de espaço perivascular gigante, cursando com alteração visual e associado a cefaleia.

Palavras-chave: Cefaleia secundária, Espaço perivascular, Alteração visual 